\title{
21st Century Neo-androgyny: What is androgyny anymore and why we should still care.
}

Bobbi M. Woodhill

University of New England, Armidale, Australia;

Dr. Curtis A. Samuels

University of California, Berkeley.

\section{Highlights}

- Psychological Androgyny has been an essential part of identity research since the 1970s. It now languishes in the background..

- Cultural changes, support for the masculine model, and conflation of terminology have led many researchers to abandon the notion.

- This new theory address fundamental flaws in the original model.

- We present a new theory refuting the criticisms of the traditional model.

\section{Introduction}

This paper is based on our previous theory of social (positive, desirable) and anti-social (negative, undesirable) androgyny (see Woodhill and Samuels, 2003, 2004). The concept of androgyny is a contentious and amorphous one- a conflation of the two Greek words 'andro,' meaning male, and 'gyne,' meaning female, with altered meanings over time. A wide selection of human interests use or discuss androgyny, from the sciences of biology, archaeology, anthropology, and history, to the humanities of psychology, sociology, the literary arts of history, poetry, fiction, and philosophy, and on to the visual arts.

This paper has a specific focus that can best be understood by asking what new concepts are needed to understand psychological androgyny within human bio-psycho-social development? Although sex and gender are removed from the context of androgyny in this theory, androgyny has traditionally centered on gender as a psychological construct.

The notion of androgyny in humans has referred to myriad and variable constructions of literal and figurative images of woman-in-man and man-in-woman (Ramet, 1996). According to Saenz de Tejada (1994), it was Plato, born around 420 BC, who first revealed the word 'androgyny' in his Symposium, and unification of the sexes in some form has often served as a symbol of salvation (Author 1, 2013).

When referring to people, androgyny has two forms, physical and psychological. The definition of a physically androgynous individual is the only term that is not ambivalent in the broader community and refers to a person who is partly male and partly female in appearance. Some who identify as non-binary or genderqueer choose an appearance that matches their innately androgynous gender identity (see later). 
With patriarchy being the history of the world and expectations of women restricted to the domestic and decorative, feminist researches of the 1970s (Constantinople, 1973; Heilbrun, 1973; Block, 1973; Bem, 1974; Spence, Helmreich, \& Stapp, 1974; Maccoby \& Jacklin, 1974; Secor, 1974; Hefner, Rebecca, \& Oleshansky, 1975; Chodorow, 1978) saw a chance to dilute the social hierarchy in the race for equality. Spelman (cited in Gould, 1997) upheld a general principle of feminist inquiry - to be skeptical about any account of human relations that fail to mention gender.

Early feminist researchers believed differences prescribed based on biological sex were flawed and viewed androgyny as a tool to defeat the politics of patriarchy and minimize difference. For feminists, difference was tied to culture and society and not to biology.

Feminist androgyny was loosely defined as psychological and the presence within the one individual of both masculine and feminine traits, skills, and interests that are stereotypically associated with masculinity and femininity (Lenney, 1979; Elshtain, 1981). But wait, there's more. Combining masculinity and femininity was seen as potentially of most significant benefit to all individuals in terms of skills or behavioural styles (Morawski, 1987).

The androgyny 'hypothesis' stated that being androgynous enabled sex-role transcendence and is positively correlated with higher levels of psychological health and well-being for both sexes (Bem, 1974). Feminist researchers set about finding proof of the hypothesis.

\section{Is the idea of psychological androgyny still relevant?}

Androgyny has been an essential part of identity research; however, while the promises of the androgyny hypothesis still seem intuitively attractive, these have not been unequivocally substantiated. Cultural changes, support for the masculine model (Kark, 2020), and conflation of terminology have led many researchers to abandon the notion of androgyny (Woodhill and Samuels, 2021b). Indeed androgyny as a gender identity seems to have been somewhat discredited as wishy-washy (Kimmel, 2000).

Additionally, too many studies have remained linked to categorical sex (Vantieghem, Vermeersch, \& Van Houtte, 2014). Indeed, the paucity of research on androgyny since the 1980s would seem to confirm it as an outdated concept, either misconceived or irrelevant to the lived experience.

Emasculation, understood in lay terms as wishy-washy masculinity, is apparent in traditional androgyny, where it implicitly asks men to adopt innate femininity. Judith Halberstam asked why there was no word for the opposite of "emasculation" (Halberstam, 1998, p. 269), and Cynthia Secor (1974, p. 166) states that androgyny is essentially a male word and, in effect, "gynandry" does not exist. We present the word 'masculation' as implicitly asking women to adopt innate masculinity.

Thus, one is prompted to ask whether or not the construct of androgyny as some mystical combination of masculine and feminine characteristics is no longer defensible. Does androgyny have a place in the Anthropocene of the 21 st century? If so, how can it be represented? 
The problems with traditional androgyny theory are multiple, yet we, as did Lenny (1979), propose the shortcomings are more theoretic than psychometric. Early theorists presented psychological androgyny as a balanced mix of loosely defined masculinity and femininity and measured it categorically. By 'loosely defined,' we mean an unspecific collection of innate traits and non-innate behaviors. Traditionally, masculinity has been tied to instrumental traits and femininity to expressive traits. Up to the 1970 s, these differences were politicized hierarchically with instrumentality privileged (Morawski, 1987).

In her critique of androgyny, Morawski (1987) blamed individual constraints, especially for women, on socio-cultural power structures. Politics, power, and culture were to blame for inequality. Morawski (1987) claimed that by falling prey to the hierarchical language of difference established by ancient male-dominated science and maintaining innate differences, early researchers of androgyny theory appeared to operate in a 'social vacuum' (Morawski, 1987). For the defeatists of androgyny, politics and social structures and not any innateness in gender affect individual locus of control and broader choices.

Traditional models of androgyny ignored the socio-political drives of behavior, and the possibility of innate difference was either ill-defined or outright renounced. This position has overpowered the relevance of androgyny as currently defined because innate cognitive differences must be removed from its theory if it is to survive. If they are not, then the criticism that androgyny violates any natural order based on innate biological differences (Morawski, 1987; Carlson, 1995) becomes viable.

The lack of a general theory for androgyny, what Morawski referred to as "psychological gender," were her [valid] weapons for its de-construction. Certainly, ambiguity in definitions of gender has been presented as a fundamental flaw in androgyny theory, obfuscating the construct itself. The belief that the opposing biological gender differences are insignificant to non-existent and manufactured for the political convenience of the androgyny era had kept androgyny research problematical (Morawski, 1987). Over the issuing decades, testing of ideas associated with androgyny has declined (Martin, Cook, \& Andrews, 2017). Additionally, doubts about the validity of assessing only positive, socially desirable attributes in the measure of androgyny were first raised in 1977 (Kelly, Caudill, Hathorn, \& O'Brien, 1977). Pro-social and anti-social categories of androgyny were elaborated on by Woodhill and Samuels, who found that only pro-social androgyny was associated with optimal psychological health and well-being (Woodhill and Samuels, 2003, 2004). By maintaining innate differences, researchers of androgyny theory appear to have operated in a 'social vacuum' (Morawski, 1987).

Bem (1974) stipulated that an androgynous gender identity might allow an individual to engage in both 'masculine and 'feminine behaviors freely. However, as we noted, the social push to adopt this nebulous androgynous identity may threaten an individual's inner sense of self and suppress individual effectiveness (Carlson, 1995). 
The original categorical constructs and measures of psychological androgyny [such as the BSRI, the PAQ, and the EPAQ] showed M and F as multidimensional and uncorrelated to bodily sex (Martin et al., 2017; Palan, Areni, \& Kiecker, 1999).

Nonetheless, the scales were likely theoretically ungrounded (Ruscio \& Ruscio, 2008; Morawski, 1987), lacking any account of negative behaviors (Woodhill and Samuels, 2003), and failed to include intellect, attitudes, and behaviors not indicative of either sex, such as social poise, intellect, social competence, and creativity (Bunnett, 2020; Lefkowitz \& Zeldow, 2006).

No grand theory of psychological androgyny has been forthcoming from empirical results based on its traditional construct and measurement; in fact, one could argue that the empirical results so far almost refute the traditional theory founded on an un-defined combination of the Masculine and the Feminine.

Empirical research into the benefits of androgyny has been inconclusive. Nonetheless, androgyny research has been a vital part of identity research that cannot be ignored (Vantieghem et al., 2014).

\section{What are the implications?}

While it is valid to ask to what extent are the reported innate differences between the sexes due to physiological differences (the intrauterine organizational effects of genes and hormones) and to psychosocial factors (activational effects of the post-natal environment), it can be said with some confidence that factors such as genetics, hormones, and epigenetics (how nurture shapes nature) act in parallel to produce sex differences in some reproductive behavior in both the brains and bodies of males and females (Woodhill and Samuels, 2021a; Fernandez et.al., 2018; Chaplin, 2015; Diamond, 2013; Rice, Friberg, \& Gavrilets, 2012).

The study of sex and gender should perhaps be charged with offering a new framework from which improvements in psychological well-being can be re-examined.

The notion of androgyny as a balance of loosely defined masculinity and femininity gives all the signals of being outdated. Notwithstanding the demise of Bem's 1970s androgyny theory, androgyny remains a slippery construct and one that can be influenced by the zeitgeist (the socio-cultural thinking and biases of the day). From a contemporary viewpoint, innate cognitive differences must be removed from androgyny theory for it to survive as a theory of any significance.

\subsection{Sex vs gender-Unidimensional vs multidimensional}

Is there a binary of gender (brain sex) or not? If gender is binary, is it one dimension (unipolar) or multidimensional?

A recent review by Eliot, Ahmed, Khan, \& Patel (2021) on sex/gender differences presents a case for the negative - i.e., the human brain is not sexually dimorphic either structurally (accounting for overall size) or functionally, end of the story, and end of psychological androgyny as measured in 1970s terms of masculinity and femininity. However, there is a paradox in Eliot et al.'s (2021) statement that differences are 
insignificant "except for a few behaviors" (Eliot et al., 2021). Woodhill and Samuels (2021a) present an argument for the affirmative and propose that the human brain is dimorphic but with a caveat. Small to moderate gender differences in the 'few behaviors' are related to reproduction and, as such, not relevant to the notion of androgyny. Separate from these 'few behaviors' is the general mosaic of behavior available to both sexes (Joel \& McCarthy, 2017; Jones \& Lopez, 2014) that remains relevant to any theory of androgyny. Although maintaining the label 'androgyny' may seem counterproductive, to change it would be analogous to reinventing the wheel-and so we present the name 'neo-androgyny.'

From a humanities and a social science perspective, there are more issues. How do nonbinary or genderqueer identities and expressions relate, or not, to androgyny?

What about an individual whose sex-role orientation is incongruent with their gender? Answers can be found in accepting the argument that bodily sex and brain sex (gender) are distinct phenotypical states.

\subsubsection{Sex and gender as innate}

The case for innate gender distinct from bodily sex is founded on the neonatal development of dimorphic neural regions relevant only to latent reproduction and its few associated behaviors. Under this model, distinctly male and female genders (brain sex) develop from the neurology involved in the reproductive axis. The resultant dimorphic cognitive behaviors are evolutionary and significant to our sexually reproducing species (see Woodhill and Samuels, 2021a).

The innate dimorphic behaviors are reduced to those involved in the care of offspring. "Mothering and fathering are tethered to courtship that is tethered to mating behavior, which is, in turn, is tethered to the care of dependent offspring" (Woodhill and Samuels, 2021a, p. 20). All dimorphic behaviors related to reproduction are strongly associated with parenting roles, especially empathy and aggression (Woodhill and Samuels, 2021a).

Innate brain sex (gender) likely develops along a spectrum, creating the possibility of an androgynously innate gender identity about the middle of the spectrum (Woodhill and Samuels, 2021b). Such a gender identity is not the psychological androgyny relevant to this current paper. Others have referred to this androgyny as a form of neural intersex common to all brains (Joel, 2011). So innate androgyny as non-binary / genderqueer / androgynous is unrelated to the concept of androgyny.

Thus, the traits people once considered gendered have shifted historically to only those 'few behaviors' more associated with reproduction and the care of offspring, namely aggression and communion. The only behavior relevant to the construct of neoandrogyny is the remaining mosaic of cognitive behavior.

Of note, the key concepts in early androgyny theory were the terms 'agency and instrumentality' and 'communion and expressiveness.' However, "people can be various combinations of whatever the underlying constructs of gender are" (Woodhill 
and Samuels, 2004, p. 19), and it is now reasonable to suggest 'agency' be replaced with 'aggression' and 'communion' with 'empathy.' While a connection between communion and empathy is discernible, the connection between agency and aggression is less so. It must be clarified that;

A contemporary notion of aggression understands it as a competitive spirit alongside a willingness to mount violent defenses against outsiders, signifying a kind of natural selection for friendliness and characteristics that enhance mating ability, survival, and reproductive success.

(Sunstein, 2020 in Woodhill and Samuels, 2021a).

Levels of empathy (loosely defined as self-other awareness or feeling another person's response in ourselves) and aggression (as defined above) are profoundly sexually dimorphic (see Woodhill and Samuels, 2021a).

Nonetheless, we must address an argument for including them in the pool of androgynous behaviors. Indeed, under the 'neural' flexibility theory (Sporns, 2011; Yao, Bergan, Lanjuin, \& Dulac, 2017; Menger, Bettscheider, Murgatroyd, \& Spengler, 2010; Doidge, 2008), even innate behaviors may be subject to some exogenous manipulation.

Considering nurture and social experience may influence the average degree of any innately focused difference (Sisk, 2016), it means even innate dimorphic traits may be quantitively flexible to at least some degree but less so qualitatively. For example, male aggression is more direct or physical, while female aggression is more indirect or social (Li et al., 2020; Ligthart et al., 2005).

Additionally, and hereditary factors of aggression aside (Ligthart et al., 2005), research across the decades on exposure to violence, aggression, and sexual harassment has shown a connection to increased levels of psychometric complaints, aggressive expression, and anti-social behavior for both sexes (Herrmann, Seubert, \& Glaser, 2020; Anderson \& Bushman, 2001).

Concerning empathy, it seems possible to enhance people's awareness of what it is to be empathetic, but not probable to change a person's disposition to behave empathetically (Lam, Kolomitro, \& Alamparambil, 2011). Results of empathy training are moderated by gender with empathy levels and rates of response in females $>$ males (reviewed in Lam, Kolomitro, \& Alamparambil (2011). Thus, we maintain empathy and aggression as primarily innately dimorphic and removed them from the pool of available behaviors.

\section{In Brief}

The twentieth century was a time of intense interest of philosophers, psychologists, and the social sciences generally in gender-related behavior.

Despite the flaws in Bem's 1970s concept of androgyny, its introduction into research had a seminal contribution to the study of gender. Androgyny served as a social catalyst for social justice and equality like never before; it focused on the social construction of many gender roles, which were ultimately malleable (Dean \& Tate, 
2017). Undoubtedly such a legacy makes androgyny a concept that has not had its time (Weigel et al., 2020).

What remains pertinent from the original feminist research on psychology are the benefits of behavioural flexibility. In the end though, attempting to conflate political, cultural, and socially driven differences (Morawski, 1987), with innately and noninnately driven behavior with positive and negative characteristics (Woodhill and Samuels, 2021, 2004, 2003) remain the prominent confounding features of androgyny's foundational theory.

With confidence, it can be said that the remainder of the human behavioural mosaic associated with the general cognitive functions of reasoning, organization, and the execution of complex thoughts, including levels of intelligence, need be the only behaviors relevant to the theory of psychological androgyny.

\section{Current studies and Neo-androgyny}

By not distinguishing between innately sexed behavior relevant to reproduction (Woodhill and Samuels, 2021) and non-innate, acquired, or learned behavior (Maccoby \& Jacklin, 1974) in the androgynous mix, traditional models of androgyny proposed, by default, that it consists of their ambiguous combination. By presenting androgyny as this combination of fixed (innate) and flexible (learned) behaviors, traditional models proposed some emasculation of men and 'masculation' of women unacceptable to the general public.

"... regardless of the academic discussions about one-dimensionality, twodimensionality or multidimensionality, in people's heads, masculinity and femininity have been, are, and will continue to be each other's opposites"

(Vantieghem \& Vermeersch, 2014, p. 370).

Although Bem did not differentiate innate from learned behavior nor account for the socio-political causes of difference, she did, however, seem regretful over her own interchangeable use of the terms sex and gender when perhaps they should have been differentiated (S. Bem, personal communication, 17th October, 2007).

A more contemporary view of identity has the categories of male and female as 'fuzzy' (Haslam, 2002); that is, there are not two distinct categories of sex and gender. Instead, sex and gender are presented as gradations of the variables associated with all people generally, as linear and continuous (Carothers \& Reiss, 2013), or circular and continuous (van Anders, 2015), or canalized (Woodhill and Samuels, 2021b).

Studies since Bem's have highlighted the dimensional versus categorical classification of gendered behavior (Schudson et al., 2017; van Anders, 2015; Carothers \& Reis, 2013; Rosario, 2004; Reeder, 2003), or what we would refer to here as de-gendered behavior. A de-gendered concept for androgyny explicitly asks for a balance of degendered behavior, that is, the balance of non-innate behaviors.

Nonetheless, regardless of a few contemporary studies and discussions claiming an androgynous personality provides positive outcomes for individuals in pursuits such as 
medicine (Rupavataram, 2017), the arts (Jonsson \& Carlsson, 2000), science (Norlander, Erixon, \& Archer, 2000), and leadership (Powell, 2015; Way, \& Marques, 2013; Kark, Waismel-Manor, \& Shamir, 2012), support for the construct remains ambiguous (Pauletti et al., 2016). The links with high self-esteem and general positive outcomes for girls and women and their relationship with feminist beliefs (such as affirmative action, agency, autonomy, sexual refusal) of the late twentieth century was indeed complex, explaining why there were inconsistencies in the literature (Yoder, Snell, \& Tobias, 2012). We believe the hypothesis still lacks consistent theoretical and empirical support because innate cognitive differences, as represented in innate sex and gender above, must be removed from androgyny theory for it to survive.

\subsection{Neo-androgyny}

The de-gendering of androgyny as behavioural flexibility involves leaving only noninnate, acquired, or learned behaviors in the potential mix. Furthermore, behavioural flexibility calls for the shift away from historical ideas of sex and gender to the contemporary theory that dimorphic gendered behavior comprises only those 'few behaviors' more associated with reproduction and the care of offspring (Woodhill and Samuels, 2021a). The remainder of the human behavioural repertoire is available to anyone of either sex. Neo-androgyny as behavioural flexibility means, in essence, only non-innate, acquired, or learned behaviors are flexible and available in sufficient quantities to both sexes in support of situationally appropriate behavior and better outcomes in terms of psychological well-being.

Our focus here is on the social or positive behaviors because negative behaviors override the positive benefits of pro-social androgyny where outcomes for pro-social androgyny are different from and superior to anti-social or negative androgyny on measures of psychological health (Wajsblat, 2011; Woodhill and Samuels, 2003, 2004). Whether it is preferable to maintain the use of the word ' androgyny' in the term 'neoandrogyny' with its inherent behavioural flexibility or not, only time will tell.

\subsubsection{Method}

In previous research, higher levels of affect (as subjective well-being or general happiness and sense of well-being), social esteem (as social competence, or social esteem in social situations), self-esteem (as self-confidence in one's self, alone or in groups), acceptance of others (as feelings of acceptability of and to others), and locus of control (as the notion of self-efficacy when people believe that they are personally responsible for their life outcomes and that they are not totally at the mercy of uncontrollable, external events such as luck or fate), were identified in positively androgynous individuals (Woodhill and Samuels, 2003). Theoretically, these personality processes could give us a global picture of the positively androgynous person in today's world.

On close examination, we similarly identified five factors that drove the outcomes of higher levels of affect, social esteem, self-esteem, acceptance of others, and locus of 
control, identified previously by Woodhill and Samuels (2003): Capability, Creativity, Eminence, Social Efficacy, and Determination (as defined below). For example, social esteem and self-esteem are arguably related to capability in that they require high levels of rationality, practicality, resourcefulness, open-mindedness, helpful attitude, clearthinking, stability, and confidence. Creativity is related to high levels of either musical ability, global artistic ability, or merely an imaginative mind. Locus of control is arguably related to eminence in that eminence requires one to be worldly, socially attractive, successful, passionate, ambitious, and strong or agentic. Social efficacy is heavily reliant on being friendly, fair, fun, courteous, able to communicate well, pleasant and cheerful, sociable, dedicated, and calm. Moreover, determination is dependent on persistence, being dignified, firm, and bold.

\subsubsection{Results}

If one adheres to biologically driven differences to any extent, then, as Woodhill and Samuels's $(2003,2004,2021)$ theory of sex, gender, and differentiated androgyny suggests, none of the five components of Capability, Creativity, Eminence, Social Efficacy, and Determination represent innate psychology for either sex; they do not reflect innately driven gender differences, but instead, socially learned or culturally driven behaviors. While some authors have distinguished the relationship item 'sociable' (communality) as relating to female reproductive roles (Buss, 1995; Pfaff, 2011), we, and others (see Hentschel, Heilman, \& Peus, 2019), classify it as androgynous (gender-neutral) in the current study. The developmental trajectory of sociability is comparable for males and females (Crocetti et al., 2018). Gender-neutral sociability is initially equal in both sexes, merely that women tend to value it differently to men (Krasnova, Veltri, Eling, \& Buxmann, 2017).

Significantly, all five factors are identifiable amongst the character strengths of the Values in Action (VIA) Classification of Strengths (Peterson \& Seligman, 2004); the first significant project developed deliberately from positive psychology. The five factors we identified for neo-androgyny, that were also identified directly or as synonyms by Park, Peterson, and Seligman (2004), were;

1. Capability - as skilled performance in whatever domain of life one chooses. It subsumes such behaviors as practical, resourceful, rational, and transparent thinking.

2. Creativity — as thinking in productive ways to do things, including but not limited to strictly artistic domains. It subsumes such behaviors as artistic and musicality but is more about creative problem-solving.

3. Eminence - as being capable of leading harmoniously and respectfully, encouraging your group to get things done. Eminence subsumes such behaviors as worldly, energetic, and ambitious.

4. Social efficacy — or social intelligence — being aware of the motives and feelings of others and oneself, knowing what to do in different social situations, and acting appropriately. It subsumes such behaviors as being assertive, friendly, 
cooperative, compassionate, tender, patient, courteous, open, considerate, and helpful and is akin to empathy.

5. Determination - as zest, enthusiasm, and vigor, living life as an adventure, and not doing things half-heartedly. It subsumes such behaviors as persistence and dignity.

The five factors of neo-androgyny are well reflected in the theory of adaptive intelligence. Although intelligence consists of various kinds, the mental processes involved in creative, analytical, practical, and intelligent thinking are the same (Sternberg, 2020). Adaptive intelligence, on the other hand, is quite different from the traditional IQ test of cognitive intelligence. Adaptive intelligence is somewhat akin to Howard Gardner's theory of multiple intelligences (see Gardner, 2011), except it adds social intelligence. Adaptive intelligence, like androgynous principles, stresses the importance of interpersonal or social intelligence and creative, analytical, and wisdombased skills. Furthermore, adaptive intelligence is the "ability to set and accomplish personally meaningful goals in one's life, given one's cultural context" (Sternberg, 2020).

\section{Discussion}

While we acknowledge that our five factors do not capture the full content of behavior, one may argue that they capture their character strengths, as do Park, Peterson, and Seligman (2004).

Various components of our neo-androgyny factors are virtually tautological with the hope, zest, gratitude, curiosity, love, modesty, and intellectual strength that Park, Peterson, and Seligman found strongly associated with "life satisfaction" (Park, Peterson, \& Seligman, p. 607, 2004). Our results are not too far removed from the framework of the Big Five personality traits of openness to experience (inventive/curious vs. consistent / cautious); conscientiousness (efficient / organized vs. extravagant / careless); extraversion (outgoing / energetic vs. solitary / reserved); agreeableness (friendly / compassionate vs. critical / rational); and neuroticism (sensitive / nervous vs. resilient / confident) often associated with mental health (Lefkowitz \& Zeldow, 2006).

As Aristotle suggested, well-being is not necessarily an eventual consequence of virtuous action but somewhat inherent in such action (Ameriks \& Clarke, 2000). Thus, it would be difficult to argue that any combination of positive behaviors under the patronage of our five factors would not be more beneficial to psychological health and well-being. Interestingly, intending to broaden the scope of positive human functioning, Wajsblat (2011) sought to offer the field of positive psychology a better understanding of one positive individual behavior - that of gender role identity. Her analysis of the component factors of the Big 5 indicated that socially desirable traits associated with masculinity and femininity did add significant variance to self-report of well-being when controlling for Neuroticism and Extraversion. 
'Groups' of people are all-female, all-male, or some combination of both, and as such, this ratio is a statistical confound when ignored in psychological research. It is also why lay reports of 'people' doing such and such are an unsatisfactory representation of events; they refer to 'people' across the board when it is often to one sex or the other. The anonymous notion of 'groups' conflates dimorphic behavior into one sex, whereas our factors do not attempt to classify $\mathrm{M}$ and $\mathrm{F}$ behavior as that would reinforce the very stereotypes they appear to undermine.

We suggest that the five factors of pro-social behavior identified in this study could form the basis of a new generic continuous measure of pro-social behavioural versatility (i.e., a new conceptualization of androgyny or neo-androgyny).

The theory of neo-androgyny represents a contemporary approach to behaviour. Instead of attempting to fit traits as undifferentiated masculinity and femininity into traditional theories of androgyny, this theory supports a new and more precise model of androgyny; one that makes use of the entire repertoire of pro-social behavior, once regarded as masculine and feminine to varying degrees, yet now more de-gendered and separate from innate difference. In this way, neo-androgyny may be used to identify further behavioural versatility or update the desirability status of behaviors concerning changing social and cultural norms.

\section{Limitations}

The underlying theory behind this study was developed for Western cultures. We have relaxed practical limitations in favor of exploring data relative to this new theory. Apart from Spence, Helmreich, and Holahan (1979), our attempts to address the theoretical flaws in Sandra Bem's original and significant theory are better than anything else intended to do so since. The limitations to this theory are not indifferent, and we would agree they limit its validity.

However, we also believe the paper is built on a robust theoretical foundation and is a statistical starting point for a well-grounded theory. The theory does present high heuristic support for the theory.

\section{Conclusion}

The original orthogonal two-dimensional concept of $\mathrm{M}$ and $\mathrm{F}$, as presented in the traditional androgyny theory, removed the restriction imposed by a mutually exclusive uni-dimensional model (Bunnett, 2020). Regardless, obliterating sex and gender from the theory of androgyny (herein conceptualized) has removed the need to tie androgyny theory to any concept of $\mathrm{M}$ and $\mathrm{F}$.

The significance of not removing innate traits from androgyny theory is highlighted when either their attempted dilution or removal may be regarded as a threat to a person's integrity through a perceived impact on the inner sense of self (Weigel et al., 2020). The attempted merging of innate masculine and feminine characteristics may suppress effectiveness in services such as management, the military, in people generally unable to integrate parts of their masculine and feminine selves (Carlson, 1995). In 
other words, whether one believes in innate behavior differences or not, the traditional notion of being androgynous merged fundamental or imagined differences which may threaten an individual's inner sense of self and hence bring fear of adopting an androgynous lifestyle.

This theory lays the ground for the regeneration of androgyny theory and the basis of a new empirical replacement of antiquated categorical measures of androgyny. Therefore the androgyny hypothesis, which states that being androgynous enables sex-role transcendence and is positively correlated with higher levels of psychological health and well-being for both sexes, may be re-examined.

By default, traditional androgyny theory is seen as challenging personal identity and is inconsistent with today's diversity. In contrast, neo-androgyny is not a call to challenge group or individual identities or de-gender emotional states or individual traits or temperaments. Neo-androgyny may become a mindset model by not attempting to degender the sexes or interfere with individual identity, thus addressing concerns with the traditional model. Future studies could assess the validity of a measure of $\mathrm{A}+\mathrm{de}-$ gendered androgyny based on the factors identified in this theory and assess the theory by comparing the predictive abilities of $\mathrm{A}+$ de-gendered factors and traditionally gendered androgyny.

The significance of stable innate behavioural difference does not negate the benefits of this neo-androgyny because politically gendered, and socially determined behavior is inherently gender-neutral and is distinct from, and can co-exist with, innate behaviors whether one believes they exist or not.

Despite androgyny's ambiguous past and that it was once discredited as a kind of wishy-washy gender identity for either sex, we do admire those amongst us who can express the virtues of both sexes (Woodhill and Samuels, 2004).

Up to the 1970s and beyond, masculinity has been tied to instrumental traits and femininity to expressive traits. Moreover, these differences were politicized hierarchically with instrumentality privileged. Early theorists presented psychological androgyny as a balanced mix of loosely defined masculinity and femininity and measured it categorically. The theory of neo-androgyny does not deny inborn differences since it neither calls for men to express innate 'femininity' nor women to express innate 'masculinity.'

It is significant to note that a neo-androgynous identity promotes and validates the momentum towards more acceptable and adaptive behavior amongst men and women no matter how they identify, without the threat to self-esteem, earlier feminist versions of androgyny produced through their implicit denial of innate sex differences.

From the pool of non-essential behaviors, the neo-androgynous person may possess social behaviors often restricted for their sex. Neo-androgyny may allow a broader range of attitudes, values, trait dispositions, and interests to build a more fulfilling renaissance kind of life (Hefner, Rebecca, \& Oleshansky, 1975; Woodhill and Samuels, $2003,2004)$, that is, a life of renewable interest typified by a degree of happy naivety. 
The Renaissance emphasis is historically humanist and androgynous, both independent to and concerning the supernatural; it is regarded as a watershed in the development of civilization (Drabble, 1992). For both sexes, neo-androgyny dictates the certainty of including opposite-sex, non-essential, psychological behaviors and merely the potential to include the roles, experiences, and skills once associated with the opposite sex. This research has correspondingly adopted the transcendent representation of androgyny provided by the Brazilian author Clarice Lispector.

According to Lispector (cited in Saenz de Tejada, 1994), the balance provided by androgyny creates a union of opposites at all levels. Theoretically, there is a minimum separation of the masculine and feminine into the conscious; the 'Id' is androgynous. Additionally, individual androgyny expands into a humble tolerance of and openmindedness towards the essential and cultural aspects of the other sex and the subsequent reconciliation of many sex-typed dichotomies.

An androgynous person does not pretend to be a member of the opposite sex. An androgynous male will not repress his feminine characteristics, however much he may decide at times to suppress them...He knows there will be times when he will choose to think and perhaps behave according to the "her" within him.

(Lispector cited in Saenz de Tejada, 1994, p. 41).

This, in turn, may convey the realization, cherishing, and expression of opposite sex strengths. For example, androgynous governance may consist of strong, assertive capabilities combined with a wholesome sensitivity to others. Masculinity and femininity are often defined in performative terms only (Spence, 1995); however, in Lispector's definition, androgyny is the symbolic union of opposites at all levels of human existence (Saenz de Tejada, 1994). This union makes androgynous people somewhat "spiritual hermaphrodites" (Landow, n.d.), acknowledging that at higher realms of awareness, there is no separation of male and female, excluding that relevant to reproduction, into the conscious. Under this androgynous symbolism, men and women may maintain all facets of non-essential sex and gender synchronously and egalitarian respect for the innate traits and behaviors of the opposite sex. Arguably, if one values a behavior, one will respect it - an argument often put forward to reduce male violence towards women. Because the androgyne is potentially less judgmental and less hierarchical, androgyny may be associated with independent freedom of thought, a keen social conscience, and a high level of morality, or as presented by some, as the means to civilized and moral, societies (Woolf, 1929; Bell, 1932; Heilbrun, 1973).

The five factors of de-gendered pro-social androgyny: Social Efficacy, Creativity, Capability, Eminence, and Determination, are therefore available to be used in good service of the expression of all other behaviors, traits, temperaments, goals, interests, interests, occupational skills, and hobbies. Under the androgyny hypothesis, these factors in turn, gives access to more excellent psychological health and well-being. Women [and men] routinely exhibit both stereotypical and non-stereotypical characteristics. For example, pregnancy calls for agency from women-when agency is 
culturally regarded as stereotypically male (non-stereotypical female behavior), while marriage calls for communality both for men and women when it is stereotypically female. It is possible to identify discrete life situations that call for more or less stereotypical masculine or feminine behaviors (Abrahams, Fieldman, \& Nash, 1978). For example, for men to marry and care for a child means establishing and maintaining intimate relationships with another person that requires affection, warmth, and concern for the well-being of others - qualities that are commonly perceived as feminine and non-stereotypical of men.

Because of the social stigma associated with behavioural diversity, all identities may still face pressure to produce behaviors that confirm role expectations. How might we reduce stereotyped thinking and encourage children to be more flexible about their interests and attitudes? Some theorists (Orlofsky, 1979; Bem, 1993, 1998; Woodhill and Samuels, 2004) believe that androgynous parenting raises androgynous children. Nevertheless, how might we teach children who have already received numberless gender-stereotyped messages from families, peers, teachers, and the media?

The discrepancy in levels of aggression and empathy between men and women are remarkable (Woodhill and Samuels, 2021a), and it comes as no surprise to learn of the failure in empathy training (Lam, Kolomitro, \& Alamparambil, 2011). However, various other studies claim that cognitive development interventions, showing men and women participating side by side in traditionally masculine (e.g., policing) or feminine (e.g., nursing) occupations, can be highly effective at combating rigid stereotypes in young children who come from more traditional backgrounds (Block, 1973; Bigler \& Liben, 1992; Shaffer, 2002). For example, The Daring Book for Girls (Buchanan \& Peskowitz, 2007) is a post-modern narrative for young girls to broaden their attitudes, interests, and skills. However, this side-by-side role sharing is not, like neo-androgyny, necessarily about being skilled in both male and female ways, but more openness and flexibility of opinion.

Although individual traits and behaviors are dependent on the sum of many factors such as genetics, hormones, temperament, and contextual influences like moral, political, and religious identity, the learned component is flexible and alterable during the complete lifespan. Most everyone can learn many effective behaviors, from the tumultuous early childhood years, through adolescent identity achievement, on to the relatively stable adult years.

\section{The future of androgyny theory and why we need care.}

Although we do not present neo-androgyny as a panacea, identity 'achievement' is the goal and best resolution in life, and not everyone achieves a clear identity for themselves.

Relationships always underline how the way we humans come to be ourselves. The adult years may be relatively stable, but for many, they are not. There is much to master in our adult developmental years in becoming a 'mench' (a good person) and leaving the next generation better off for our existence. 
With gender politics removed from androgyny theory, we can focus on a far-reaching picture. Adopting a neo-androgynous life may change thinking and especially the interpretation of opposite sex roles from hostile or indifferent to positive. Being androgynous may facilitate more flexible preconceptions about other identities.

It is undoubtedly not an exaggeration to conclude that repression of significant parts of capability, creativity, eminence, and social efficacy in either sex is antithetical to psychological health and well-being (Author 1, in press). As we noted, there is a relationship between androgyny and the means to Civilization (Bell, 1932).

Societies consist of people, and Clive Bell noted the connection between androgyny as the barometer of social health. Bell suggested a link between androgyny and the means to civilization and that in an androgynous society, the virtues of women flourished.

Societies that subvert feminine virtue fail to thrive (Bell, 1932). Egalitarian foundations and social health are arguably destroyed in imperfect non-androgynous societies.

Freud (2005) proposed that psychopathology may result from the denial of the nature of individuals and further that the status of women in non-androgynous societies is impoverished. According to Carolyn Heilbrun (1973), where men's and women's roles can be reversed without appearing ludicrous or perverted, is an essential imperative.

Heilbrun (1973) also commented on Clive Bell's discussion of the position of women in civilized societies and the connection between androgyny, the means to civilization, and society. Bell had recognized that in an androgynous society, the virtues of women flourished.

"...women being, in more ways than the obvious, means to civility... and that without an admixture of [mitigated or socially androgynous] femininity; such like feminine attitudes, values, sensitivity, perception, intuition, wit, subtlety, devotion, and perversity, a civilization must remain lop-sided and incomplete"

(Bell, 1932, pp. 232-233).

In contrast, Bell asserted that women of his time were at a disadvantage and that "...there they will remain until they have got the work of mother and housewife put on precisely the same footing as that of mechanic or barrister" (Bell, 1932, p. 233).

Archetypal examples of over masculinized societies are those where male principles of competition, control, power, and dominance are centerstage. These cultures are also about the men who 'own' women and the ferocious control of women (Benson \& Stangroom, 2009). Examples of such societies worldwide where this is the case and fail to thrive are clear-cut.

Heilbrun later expressed despair for androgyny that appears to be based on fearing a uni-sexed world of lost etiquettes. She and Morawski (1987) suggest androgyny threatens some men and women more profoundly in their sexual rather than social roles. Historically humans have been divided by gender and not by talent, desire, or attribute (Heilbrun, 1973). Heilbrun and others (Bakan, 1979; Mead, 1949; Gardner \& Stern 2002) claim there is sufficient evidence from mythology and anthropology to suggest 
when the feminine principle prevailed, i.e., of matriarchal societies. Heilbrun's feminist critique of patriarchy parallels Bell's in that it is based on the argument that matriarchy brings a special civilizing force to societies, suchlike sensitivity, affection, justice, and compassion. Compare this to masculinized societies. However, Heilbrun claims alertness to a danger that Mary Ann Evans (George Eliot) had expressed, where "We women are in danger of living too exclusively in the affections.... and that they should also delight in things" (Heilbrun, 1973, p. 76).

The androgynous person may change their interpretation of opposite sex roles from hostile or indifferent to positive, allowing more flexible preconceptions. Moreover, androgyny may be associated with independent freedom of thought, a keen social conscience, and a high level of morality because the androgyne is less judgmental and less hierarchical. For example, societies where fathers are more involved in regular child-care, are more egalitarian (Evertsson, 2014; Hewlett, 2000; Aldous, Mulligan, \& Bjarnason, 1998).

The relationship between androgyny and civilized societies is logical in that if one adopts a behavior, one respects it, and in turn respects others who possess that behavior, which in turn drives equality, and equality leads to equal representation, which leads to political balance and women's equal representation in positions of power, which in turn leads to the balance of masculine and feminine principles across cultures. Generation Alpha (2010 - 2024) will also likely need high levels of leadership, empathy, and creativity to remain empowered and future-proofed (McCrindle \& Fell, 2021)

Thus, in the individual androgynous life and in that of the collective consciousness of societies (Jung, in Read \& Adler, 1959) built on androgynous principles, superlative moral reasoning has little relevance.

\section{Declaration of interest.}

Conflict of interest: The authors have no competing interests to declare.

Funding. This paper did not receive any specific grant from funding agencies in the public, commercial, or not-for-profit sectors.

Availability of data and material. Not relevant

\section{CRediT author statements.}

Author 1. Conceptualization; Project administration; Resources; Software; Supervision; Writing - original draft \& editing; Writing - review \& editing.

Samuels, C: Project administration; Resources; Software; Supervision; Writing - review \& editing. 


\section{References}

Abrahams, B., Feldman, S., \& Nash, S. (1978). Sex role self-concept and sex role attitudes: Enduring personality characteristics or adaptations to changing life situations?. Developmental Psychology, 14(4), 393.

Aldous, J., Mulligan, G., \& Bjarnason, T. (1998). Fathering over time: What makes the difference?. Journal of Marriage and the Family, 809-820.

Ameriks, K., \& Clarke, D. (2000). Aristotle: Nicomachean Ethics. Cambridge University Press.

Anderson, C., \& Bushman, B. (2001). Effects of violent video games on aggressive behavior, aggressive cognition, aggressive affect, physiological arousal, and prosocial behavior: A meta-analytic review of the scientific literature. Psychological science, 12(5), 353-359.

Bakan, D. (1979). And they took themselves wives. New York: Harper \& Row.

Bell, C. (1932). Civilization. London: Chatto \& Windus.

Bem, S. (1974). The measurement of psychological androgyny. Journal of Consulting and Clinical Psychology, 42, 155-162.

Bem, S. (1993) The Lenses of Gender. Yale University Press, New Haven.

Bem, S. (1998). An Unconventional Family. New Haven, CT: Yale University Press.

Benson, O., \& Stangroom, J. (2009). Does God hate women? London: Continuum.

Bigler, R., \& Liben, L. (1992). Cognitive mechanisms in children's gender stereotyping: Theoretical and educational implications of a cognitive-based intervention. Child Development, 63, 1351-1363.

Block, J. (1973). Conceptions of sex role: Some cross-cultural and longditudinal perspectives. American Psychologist (June), 512-526.

Buchanan, A., \& Peskowitz, M. (2007). The daring book for girls. New York: HarperCollins.

Bunnett, E. R. (2020). Androgyny, Expression of. The Wiley Encyclopedia of Personality and Individual Differences: Personality Processes and Individual Differences, 25-30.

Buss, D. (1995). Evolutionary Psychology: A new paradigm for psychological sciences. Psychological Enquiry, 6, 1-30.

Carlson, C (1995). The Androgyny Hoax. Retrieved from https://www.pop.org/theandrogyny-hoax/ Visited April 11, 2021.

Carothers, B., \& Reiss, H. (2013). Men and women are from earth: Examining the latent structure of gender. Journal of Personality \& Social Psychology, 104, 2, 385-407. doi: $101037 / \mathrm{a} 0030437$ 
Cattell, R. (1966). The scree test for the number of factors. Multivariate Behavioural Research, 1, 245-276.

Chaplin, T. (2015). Gender and emotion expression: A developmental contextual perspective. Emotion Review, 7(1), 14-21.

Chodorow, N. (1978). The reproduction of mothering: Psychoanalysis and the sociology of gender. Berkeley: University of California Press.

Constantinople, A. (1973). Masculinity - Femininity: An exception to a famous dictum. Psychological Bulletin, 80(5), 389 - 407.

Dean, M., \& Tate, C. (2017). Extending the legacy of Sandra Bem: Psychological androgyny as a touchstone conceptual advance for the study of gender in psychological science. Sex Roles, 76(11-12), 643-654.

Diamond, M. (2013). Transsexuality among twins: identity concordance, transition, rearing, and orientation. International Journal of Transgenderism, 14(1), 24-38. doi:10.1037/h0077098.

Doidge, N. (2008). The brain that changes itself. Melbourne: Scribe.

Drable, M. (1992). The Oxford companion to English literature. Oxford: Oxford University Press.

Eliot, L., Ahmed, A., Khan, H., Patel, J. (2021). Dump the “dimorphism”:

Comprehensive synthesis of human brain studies reveals few male-female differences beyond size. Neuroscience \& Biobehavioural Reviews, in press.

doi.org/10.1016/j.neubiorev.2021.02.026.

Elshtain, J. (1981). Against androgyny. Telos, 47, 5-21.

Evertsson, M. (2014). Gender ideology and the sharing of housework and child care in Sweden. Journal of Family Issues, 35(7), 927-949.

Fernández, R., Guillamon, A., Cortés-Cortés, J., Gómez-Gil, E., Jácome, A. (2018).

Molecular basis of Gender Dysphoria: androgen and estrogen receptor interaction. Psychoneuroendocrinology, 98, 161-167.

Freud, A. (2005). Human sexuality. In J. Strachey (Ed.), Essentials of psychoanalysis. London: Vintage.

Gardner, G., \& Stern, P. (2002). Environmental problems and human behaviour. Boston: Pearson Custom Publishing.

Gardner, H. (2011). Frames of mind: The theory of multiple intelligences (10th anniversary ed.). New York, NY: Basic Books.

Gough, H., \& Heilbrun, A. (1980). The Adjective checklist manual. Palo Alto, CA: Consulting Psychologists Press.

Gould, C. (1997). Gender: Key concepts in critical theory. Amherst, New York: Humanity Books. 
Halberstam, J. (1998). Female masculinity. Duke University Press.

Haslam, N. (2002). Kinds of kinds: A conceptual taxonomy of psychiatric categories. Philosophy, Psychiatry, \& Psychology, 9(3), 203-217.

Hefner, R., Rebecca, M., \& Oleshansky, B. (1975). Development of sex-role transcendence. Human Development, 18, 143-158.

Heilbrun, C. (1973). Towards androgyny. London: Victor Gollancy.

Hentschel, T., Heilman, M., \& Peus, C. (2019). The multiple dimensions of gender stereotypes: A current look at men's and women's characterizations of others and themselves. Frontiers in psychology, 10, 11.

Herrmann, A., Seubert, C., \& Glaser, J. (2020). Consequences of exposure to violence, aggression, and sexual harassment in private security work: a mediation model. Journal of interpersonal violence, 0886260520984432.

Hewlett, B. (2000). Culture, history, and sex: Anthropological contributions to conceptualizing father involvement. Marriage and Family Review, 29, 59-73.

Joel, D. (2011). Male or female? Brains are intersex. Frontiers of Intergretive Neuroscience, 5, 1-9. doi: 10 3389/fnint 201100057

Joel, D., \& McCarthy, M. (2017). Incorporating sex as a biological variable in neuropsychiatric research: where are we now and where should we be? Neuropsychopharmacology, 42(2), 379.

Jones, R., \& Lopez, K. (2014). Human reproductive biology. Chapter Sixteen. Academic Press.

Jonsson, P., \& Carlsson, I. (2000). Androgyny and creativity: A study of the relationship between a balanced sex-role and creative functioning. Scandanavian Journal of Psychology, 41, 269-274.

Joreskog, K. (1994). On the estimation of Polychoric correlations and their asymptotic covariance matrix. Psychometrika, 59, 381-389.

Jung, C. (1959). The archetypes and the collective unconscious. In M. F. Herbert Read, Gerhard Adler (Ed.), The collected works of C.G.Jung (Vol. 9). London: Routledge.

Kaiser, H. F. (1960). The application of electronic computers to factor analysis. Educational and Psychological Measurement, 20, 141-151.

Kark, R. (2020). Androgyny. Encyclopedia of personality and individual differences, 160-166.

Kark, R., Waismel-Manor, R., \& Shamir, B. (2012). Does valuing androgyny and femininity lead to a female advantage? The relationship between gender-role, transformational leadership and identification. The Leadership Quarterly, 23(3), 620640 . 
Kelly, J., Caudill, M., Hathorn, S., \& O'Brien, C. (1977). Socially undesirable sexcorrelated characteristics: Implications for androgyny and adjustment. Journal of Consulting and Clinical Psychology, 45(6), 1185.

Kimmel, M. (2000). The gendered society. New York: Oxford University Press.

Krasnova, H., Veltri, N., Eling, N., \& Buxmann, P. (2017). Why men and women continue to use social networking sites: The role of gender differences. The Journal of Strategic Information Systems, 26(4), 261-284.

Lam, T., Kolomitro, K., \& Alamparambil, F. (2011). Empathy training: Methods, evaluation practices, and validity. Journal of Multidisciplinary Evaluation, 7(16), 162200.

Landow, G. (n.d.). Swinburne's philosophy of androgyny.

http://www.victorianweb.org/authors/swinburne/swinburne1.html Visited April 2, 2020

Lefkowitz, E., \& Zeldow, P. (2006). Masculinity and femininity predict optimal mental health: A belated test of the androgyny hypothesis. Journal of Personality Assessment, 87(1), 95-101. doi:10.1207/s15327752jpa8701_08

Lenny, E. (1979). Androgyny: Some audacious assertions toward its coming of age. Sex Roles, 5(6), 702-719.

Li, Q., Xiao, M., Song, S., Huang, Y., Chen, X., Liu, Y., \& Chen, H. (2020). The personality dispositions and resting-state neural correlates associated with aggressive children. Social cognitive and affective neuroscience, 15(9), 1004-1016.

Ligthart, L., Bartels, M., Hoekstra, R., Hudziak, J., \& Boomsma, D. (2005). Genetic contributions to subtypes of aggression. Twin Research and Human Genetics, 8(5), 483491.

Maccoby, E., \& Jacklin, C. (1974). The Psychology of Sex Differences. Stanford, CA: Stanford University Pres.

Martin, C., Cook, R., \& Andrews, N. (2017). Reviving androgyny: A modern day perspective on flexibility of gender identity and behavior. Sex Roles, 76(9), 592-603.

Mead, M. (1949) Male and female. New York: Harrow.

Menger, Y., Bettscheider, M., Murgatroyd, C., \& Spengler, D. (2010). Sex differences in brain epigenetics. Epigenomics, 2(6), 807-821.

Morawski, J. (1987). The troubled quest for masculinity, femininity, and androgyny. Review of Personality and Social Psychology: Sex and Gender, 7, 44-69.

Norlander, T., Erixon, A., \& Archer, T. (2000). Psychological androgyny and creativity: Dynamics of gender-role and personality trait. Social Behavior and Personality: an international journal, 28(5), 423-435.

Orlofsky, J. (1979). Parental antecedents of sex-role orientation in college men and women. Sex Roles, 5(4), 495-512. 
Palan, K., Areni, C., \& Kiecker, P. (1999). Reexamining masculinity, femininity, and gender identity scales. Marketing Letters, 10(4), 357-371.

Park, N., Peterson, C., \& Seligman, M., (2004). Strengths of character and well-being. Journal of Social and Clinical Psychology, 23, 5, 603-619.

Pauletti, R., Menon, M., Cooper, P., Aults, C. \& Perry, D. (2016). Psychological androgyny and children's mental health: A new look with new measures. Sex Roles, 76(11-12), 705-718.

Peterson, C., \& Seligman, M. (2004). Character strengths and virtues: A classification and handbook. New York: Oxford University Press.

Pfaff, D. (2011). Man and woman: An inside story. New York: Oxford.

Powell, G., \& Butterfield, D. (2015). The role of androgyny in leader prototypes over four decades. Gender in Management: An International Journal.

Ramet, S. (1996). Gender reversals and gender cultures. London: Routledge.

Reeder, H. (2003). The effect of gender role orientation on same- and cross-sex friendship formation. Sex Roles, 49(3/4), 143.

Rice, W., Friberg, U., \& Gavrilets, S. (2012). Homosexuality as a consequence of epigenetically canalized sexual development. The Quarterly review of biology, 87(4), 343-368.

Rosario, V. (2004). The biology of gender and the construction of sex? GLQ: A Journal of Lesbian \& Gay Studies, 10, 280-287.

Rupavataram, S. (2017). Shouldn't Competence and Compassion Coexist in Medical Professionals? A Study of Psychological Androgyny in Doctors. Indian Journal of Public Health Research \& Development, 8(4), 458-462.

Ruscio, A., \& Ruscio, J. (2008). Categories and dimensions: Advancing psychological science through the study of latent structure. Current Directions in Psychological Science, 17, 203-207. doi:10.1111/j.1467-

Saenz de Tejada, C. (1994). The eternal non-difference: Clarice Lispector's concept of androgyny. Luso-Brazilian Review, 31(1), 39-56.

Savalei, V., Bonett, D., \& Bentler, P. (2015). CFA with binary variables in small samples: A comparison of two methods. Frontiers in psychology, 5, 1515.

Schudson, Z., Dibble, E., \& van Anders, S. (2017). Gender/sex and sexual diversity via sexual configurations theory: Insights from a qualitative study with gender and sexual minorities. Psychology of Sexual Orientation and Gender Diversity, 4(4), 422.

Secor, C. (1974). Androgyny: An early reappraisal. Women's Studies: An Interdisciplinary Journal, 2(2), 161-169.

Shaffer, D. (2002). Developmental psychology: Childhood and adolescence (6th ed.). Stamford, CT: Wadsworth. 
Sisk, C. (2016). Hormone-dependent adolescent organization of socio-sexual behaviours in mammals. Current opinion in neurobiology, 38, 63-68.

Spence, J. (1995). Gender-related traits and gender ideology: Evidence for a multifactorial theory. Journal of Personality and Social Psychology, 64, 624-635.

Spence, J., Helmreich, R., \& Holahan, C. (1979). Negative and positive components of psychological masculinity and femininity and their relationship to self-reports of neurotic and acting out behaviors. Journal of Personality and Social Psychology, 37, 1673-1682.

Spence, J., Helmreich, R., \& Stapp, J. (1974). The Personal Attributes Questionnaire: A measure of sex role stereotypes and masculinity-femininity. JSAS Catalogue of Selected Documents in Psychology, 4, 43-44.

Sporns, O. (2011). The human connectome: a complex network. Annals of the new York Academy of Sciences, 1224(1), 109-125.

Sternberg, R. J. (2020). Rethinking what we mean by intelligence. Phi Delta Kappan, 102(3), 36-41.

Tabachnick, B. \& Fidell, L. (2001). Using multivariate statistics. 4th edition. Needham Heights, MA: Allyn \& Bacon.

van Anders, S. (2015). Beyond sexual orientation: Integrating gender/sex and diverse sexualities via sexual configurations theory. Archives of Sexual Behavior, 1-37.

Vantieghem, W., Vermeersch, H., \& Van Houtte, M. (2014). Why “Gender" disappeared from the gender gap:(re-) introducing gender identity theory to educational gender gap research. Social Psychology of Education, 17(3), 357-381.

Wajsblat, L. (2011). Positive androgyny and well-being: A positive psychological perspective on gender role Valence. Hofstra University.

Way, A., \& Marques, J. (2013). Management of gender roles: Marketing the androgynous leadership style in the classroom and the general workplace. Organization Development Journal, 31(2), 82-94.

Weigel, N., Vodolaga, V., Shapoval, G., Kartashova, E., \& Safronenko, A. (2020). Modern Androgyny as a Manifestation of a Universal Personality. Journal of Talent Development and Excellence, 12(3s), 234-241.

Wood., W., \& Eagly, A. (2002). A cross-cultural analysis of the behavior of women and men: Implications for the origins of sex differences. Psychological Bulletin, 128, 699727.

Woodhill, B., \& Samuels, C. (2003). Positive and negative androgyny and their relationship with psychological health and well-being. Sex Roles: A Journal of Research, 48(11/12), 555-565.

Woodhill, B., \& Samuels, C. (2004). Desirable and undesirable androgyny: A prescription for the twenty-first century. Journal of Gender Studies, 13(1), 15-28. 
Woodhill, B., \& Samuels, C. (2021a). Sex vs Gender: A Biological Location for Gender, not Sex. Cambridge Open Engage. doi:10.33774/coe-2020-k7gt1-v4

Woodhill, B., \& Samuels, C. (2021b). Shades of pink and blue: Unidimensional spectra of identity within a multidimensional model of diversity. Cambridge Open Engage. doi:10.33774/coe-2021-bcw4j

Woodhill, B. (in press). Psychoanalysis and Neo-androgyny. The Psychoanalytic Review.

Woodhill (nee Hopkins), B (2013) The Bible as a medium for social engineering: Jesus as the androgynous role model. Journal of Research in Gender Studies, 3,1,78-87.

Woolf, V. (1929). A room of one's own. New York: Harcourt Brace Jovanovich.

Yao, S., Bergan, J., Lanjuin, A., \& Dulac, C. (2017). Oxytocin signalling in the medial amygdala is required for sex discrimination of social cues. Elife, 6, e31373.

Yoder, J., Snell, A., \& Tobias, A. (2012). Balancing multicultural competence with social justice: Feminist beliefs and optimal psychological functioning. The Counseling Psychologist, 40(8), 1101-1132. 